\title{
Влияние состава покровного слоя на электронные характеристики квантовых точек InAs/GaAs
}

\author{
(C) А.П. Горшков ${ }^{1}$, Н.С. Волкова ${ }^{2,3}$, П.Г. Воронин ${ }^{1}$, А.В. Здоровейщев ${ }^{2}$, Л.А. Истомин ${ }^{3}$, \\ Д.А. Павлов ${ }^{1}$, Ю.В. Усов ${ }^{1}$, С.Б. Левичев ${ }^{2}$ \\ ${ }^{1}$ Нижегородский государственный университет им. Н.И. Лобачевского, \\ 603950 Нижний Новгород, Россия \\ ${ }^{2}$ Научно-исследовательский физико-технический институт \\ Нижегородского государственного университета им. Н.И. Лобачевского, \\ 603950 Нижний Новгород, Россия \\ ${ }^{3}$ Научно-исследовательский институт химии \\ Нижегородского государственного университета им. Н.И. Лобачевского, \\ 603950 Нижний Новгород, Россия \\ E-mail: gorshkovap@mail.ru
}

(Получена 27 апреля 2017 г. Принята к печати 12 мая 2017 г.)

\begin{abstract}
Заращивание массива самоорганизованных квантовых точек InAs/GaAs слоем квантовой ямы InGaAs приводит к увеличению их размера за счет обогащения области вблизи вершины квантовых точек индием, что уменьшает энергию основного оптического перехода в квантовых точках на 50 мэВ и смещает волновую функцию дырки по направлению к вершине квантовой точки.
\end{abstract}

DOI: 10.21883/FTP.2017.11.45088.02

\section{1. Введение}

Актуальной задачей современной оптоэлектроники является формирование квантовых точек (КТ) InAs/GaAs с требуемыми для приборных применений свойствами. Например, для создания лазеров [1-3] необходимо получение КТ с энергией основного перехода, лежащей в областях прозрачности оптического волокна $(1.3,1.55$ мкм). Один из вариантов решения данной задачи связан с управлением ключевыми электронными характеристиками КТ путем изменения толщины и состава покровного слоя $\mathrm{InGaAs} / \mathrm{GaAs}$. В литературе указывают несколько причин, влияющих на энергетический спектр КТ при изменении параметров покровного слоя. Если слой КT InAs заращивается сначала слоем квантовой ямы $\operatorname{In}_{x} \mathrm{Ga}_{1-x}$ As и лишь затем покровным слоем GaAs, то происходит красное смещение оптических переходов в КТ по двум причинам: во-первых, из-за стимулированного наличием кластеров InAs pacпада твердого раствора квантовой ямы, приводящего к обогащению области вблизи вершины КТ индием [4], а следовательно, к увеличению эффективной высоты КТ; во-вторых, из-за релаксации упругих напряжений в КТ, обусловленной уменьшением рассогласования решеток [5]. Эти причины должны оказывать влияние не только на энергетический спектр КТ, но и на взаимное пространственное расположение электрона и дырки [6], информация о котором может быть получена из исследований квантово-размерного эффекта Штарка. В данной работе проведено исследование влияния заращивания KT InAs/GaAs слоем квантовой ямы InGaAs на спектр оптических переходов, дипольный момент экситона, а также размер и состав кластеров КТ.

\section{2. Методика эксперимента}

В данной работе были исследованы две структуры с KT InAs/GaAs, выращенные в группе эпитаксиальной технологии НИФТИ ННГУ методом газофазной эпитаксии из металлорганических соединений при атмосферном давлении. На поверхности (100) $i$-GaAs обеих структур последовательно выращивались буферный слой $n$-GaAs толщиной 0.6 мкм, слой КT InAs и покровный слой 0.2 мкм. В процессе роста слой КТ легировался примесью-сурфактантом висмута, что позволяло получать более однородные по размерам КТ [7]. В первой структуре покровный слой состоял из чистого GaAs, a во второй содержал квантовую яму (КЯ) $\operatorname{In}_{0.2} \mathrm{Ga}_{0.8} \mathrm{As}$ шириной 3 нм, нанесенную непосредственно на слой КТ (структура КЯ/КТ). На поверхности структур методом электронно-лучевого испарения в высоком вакууме создавался полупрозрачный выпрямляющий Аu-контакт Шоттки площадью $\approx 0.16$ мм² $^{2}$ Омический контакт к буферному слою и подложке создавался электроискровым вжиганием оловянной фольги.

Информация о спектре межзонных оптических переходов в КТ была получена методом фотоэлектрической спектроскопии. Исследовались спектры фототока при 300 К. Источником монохроматического излучения служил монохроматор Acton SpectraPro-500i с галогеновой лампой мощностью 250 Вт. Измерения производились на переменном сигнале. Для этого использовался механический оптический модулятор Stanford Research Systems SR540, работающий на частоте 130 Гц. Детектирование переменного электрического сигнала осуществлялось по стандартной lock-in методике с применением селективного усилителя Stanford Research Systems SR810. При исследовании фотоэлектрических спектров строилась 
спектральная зависимость относительной фоточувствительности

$$
S_{\mathrm{ph}}(h v)=I_{\mathrm{ph}}(h v) / L(h v),
$$

где $I_{\mathrm{ph}}(h v)$ - фототок, $L(h v)$ - интенсивность освещения в произвольных единицах.

Эффект Штарка исследовался по смещению пика основного перехода КТ на спектре фоточувствительности при подаче на диодную структуру обратного смещения. Для расчета напряженности электрического поля $F$ в КТ при различных значениях обратного смещения на диоде использовалась стандартная теория барьера Шоттки, однородно легированного полностью ионизованной мелкой донорной примесью. Концентрация доноров в буферном слое, определенная из вольт-фарадных характеристик, в структуре с КТ составила $1.5 \cdot 10^{16} \mathrm{~cm}^{-3}$, а в структуре с КЯ/КТ - 2.7 $10^{16} \mathrm{~cm}^{-3}$. Высота барьера Шоттки в обеих структурах составила $0.7 \mathrm{~B}$.

Исследования формы и состава КТ проводились на просвечивающем электронном микроскопе JEOL JEM-2100F с рентгеновским энергодисперсионным детектором X-Max Oxford Instruments. Препарирование образцов для исследования на поперечном срезе осуществлялось по стандартной технологии при помощи системы PIPS Gatan [8].

\section{3. Экспериментальные результаты и обсуждение}

На рис. 1 показаны спектры фоточувствительности $S_{\mathrm{ph}}$ структур при $300 \mathrm{~K}$. В структуре с КТ (кривая 1) пик при энергии 0.95 эВ связан с оптическим переходом между дискретными основными состояниями электрона и дырки в КТ, а при 1.03 эВ - между их первыми возбужденными состояниями. Особенность на спектре фоточувствительности при энергии 1.34 эВ связана со смачивающим слоем InAs, который в пространстве между КТ образует квантовую яму. На спектре структуры с КЯ/КТ (кривая 2) пики фоточувствительности от КТ смещены в низкоэнергетическую область на 50 мэВ. Полоса фоточувствительности с порогом около 1.26 эВ принадлежит гибридной КЯ [9], состоящей из КЯ смачивающего слоя InAs и внешней квантовой ямы $\operatorname{In}_{0.2} \mathrm{Ga}_{0.8} \mathrm{As}$, которой покрывается слой КТ перед нанесением покровного слоя GaAs. Ступенька с порогом около 1.43 эВ на спектрах обеих структур связана с собственным поглощением в матрице GaAs.

На рис. 2 показано влияние электрического поля на положение пика основного перехода в КТ в исследованных структурах. Для удобства восприятия спектры фоточувствительности на рис. 2 сглажены и разнесены по интенсивности. При приложении обратного напряжения в структуре с КЯ/КТ наблюдается красное смещение пика, а в структуре с одиночным слоем КТ пик практически не смещается. Зависимость энергии основного перехода в КТ $\left(E_{0}\right)$ от напряженности электрического

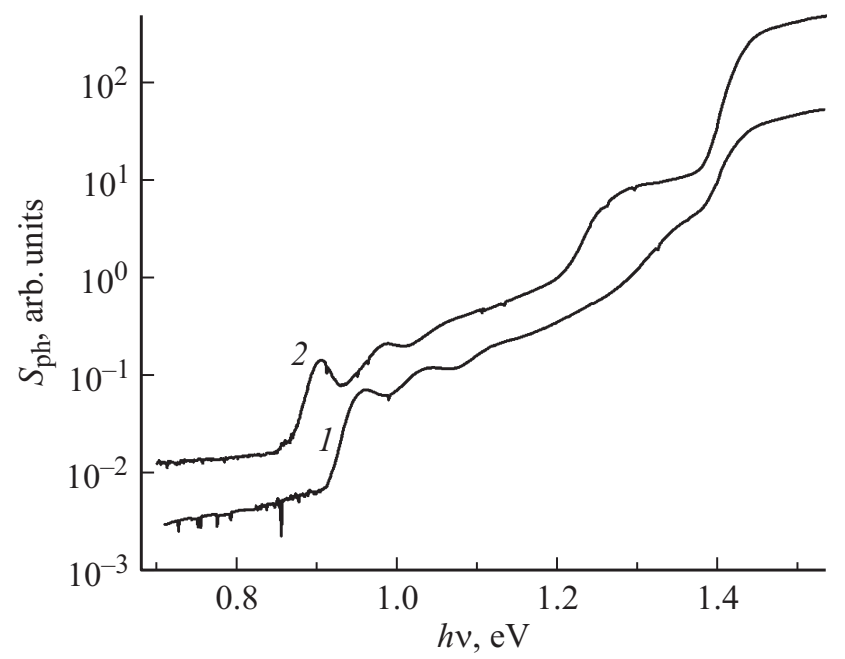

Рис. 1. Спектры фоточувствительности структур с КТ (1) и КЯ/КТ (2) при $300 \mathrm{~K}$ в отсутствие смещения на диоде Шоттки.
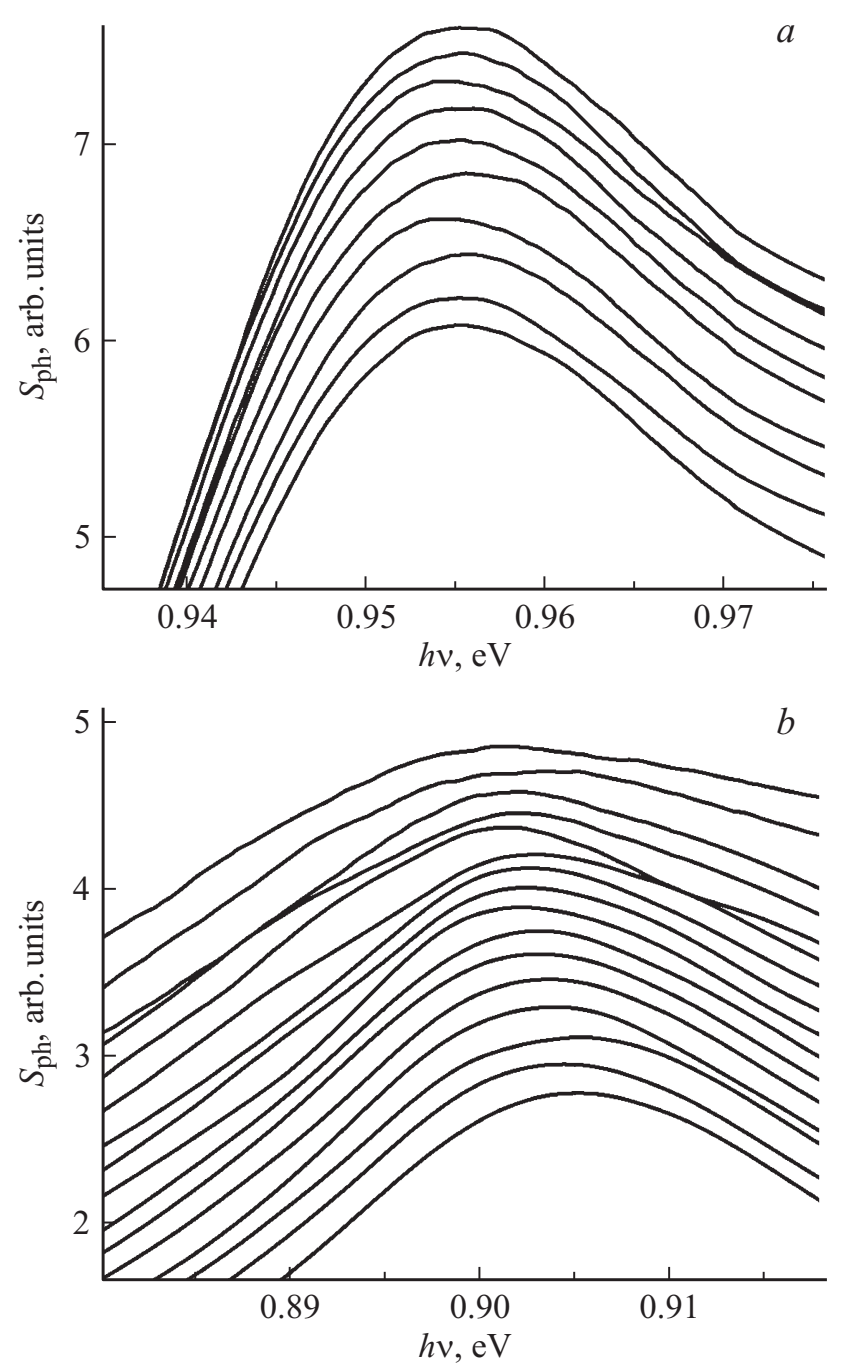

Рис. 2. Влияние электрического поля на положение пика основного перехода в КТ. $a$ - структура с КТ; напряженность электрического поля увеличивается снизу вверх от 10 до 110 кВ/см. $b-$ структура с КЯ/КТ; напряженность электрического поля увеличивается снизу вверх от 5 до 150 кВ/см. 


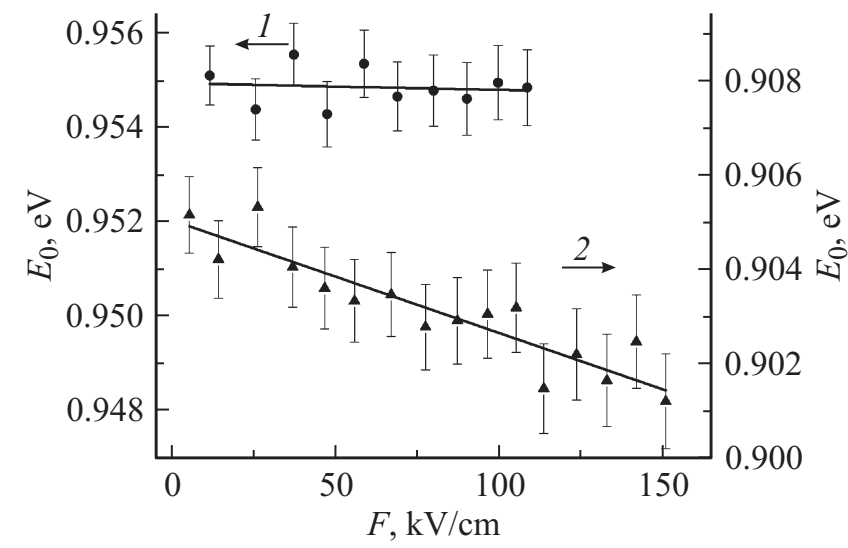

Рис. 3. Штарковский сдвиг положения экситонного пика для структур с КТ (1) и КЯ/КТ (2).

поля $F$, связанная с эффектом Штарка, в общем случае определяется выражением [10]

$$
E_{0}(F)=E_{0}(0)-(p F)-\alpha F^{2},
$$

где $E_{0}(0)$ - энергия перехода в отсутствие поля; $p$ - постоянный дипольный момент экситона в КТ, связанный с пространственным разделением центров заряда электрона и дырки в КТ в отсутствие поля; $\alpha$ - параметр, характеризующий индуцированный в электрическом поле дипольный момент КТ. Ранее проведенные исследования эффекта Штарка на аналогичных КТ, выращенных газофазной эпитаксией, показали, что штарковский сдвиг в них хорошо описывается линейным законом [11], в то время как в структурах, выращенных молекулярно-лучевой эпитаксией, обнаруживалось и квадратичное слагаемое $\alpha F^{2}[10,12]$. Такое различие в закономерностях эффекта Штарка, вероятно, связано с меньшей поляризуемостью экситона в КТ, выращенных газофазной эпитаксией, из-за более сильной локализации носителей заряда в таких КТ, поскольку энергия основного перехода в них $(\approx 0.9$ эВ $)$ существенно меньше, чем в КТ, исследованных в $[10,12]\left(E_{0} \approx 1.1\right.$ эВ). Данное предположение о линейности сдвига было принято и при анализе зависимостей $E_{0}(F)$ в обеих исследованных в данной работе структурах (рис. 3 ).

Определенный методом наименьших квадратов по наклону полевых зависимостей штарковского сдвига дипольный момент экситона в КТ в структуре с одиночным слоем КТ составил $(1.6 \pm 9.6) \cdot 10^{-28}$ Кл $\cdot$ см, а в структуре с КЯ/КТ - $(4.0 \pm 0.8) \cdot 10^{-27}$ Кл · см. Этим значениям соответствует расстояние между центрами зарядов электрона и дырки - $0.01 \pm 0.06$ и $0.25 \pm 0.05$ нм соответственно. Поскольку в структурах с барьером Шоттки на основе $n$-GaAs поле поверхностного барьера направлено от подложки к поверхности, а штарковский сдвиг отрицателен, дипольный момент экситона в КТ направлен от ее основания к вершине. Это так называемое аномальное [10] направление дипольного момента, соответствующее расположению дырки над электроном, т.е. ближе к вершине КТ. В структуре с одиночным слоем КТ можно считать, что центры заряда электрона и дырки практически совпадают. Увеличение аномального дипольного момента экситона при заращивании массива КТ слоем квантовой ямы $\operatorname{In}_{x} \mathrm{Ga}_{1-x} \mathrm{As}$ может быть объяснено смещением волновой функции дырки по направлению к вершине КТ. Данные о пространственном содержании In, полученные методом рентгеновской энергодисперсионной спектроскопии (рис. 4), указывают на то, что в структуре с КЯ/КТ действительно имеет место стимулированный распад твердого раствора квантовой ямы $\operatorname{In}_{x} \mathrm{Ga}_{1-x}$ As [4], приводящий к увеличению содержания In у вершины КТ и увеличению ее эффективного размера. Это делает потенциальную яму для электронов и дырок в области вершины КТ

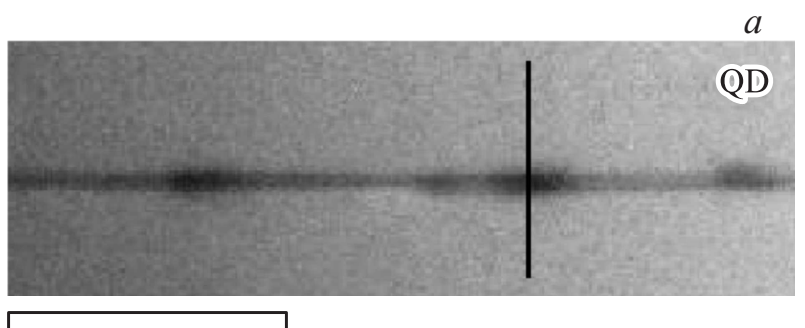

$100 \mathrm{~nm}$

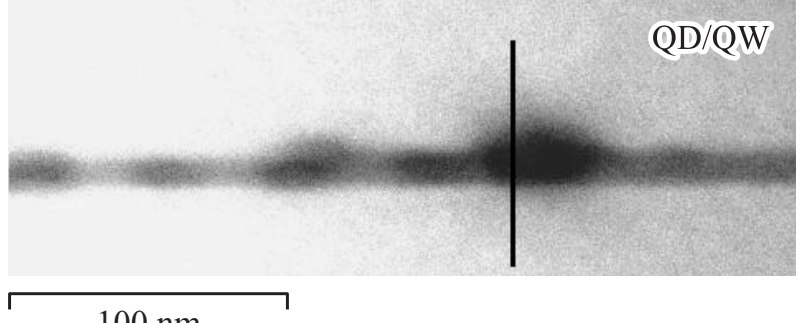

$100 \mathrm{~nm}$

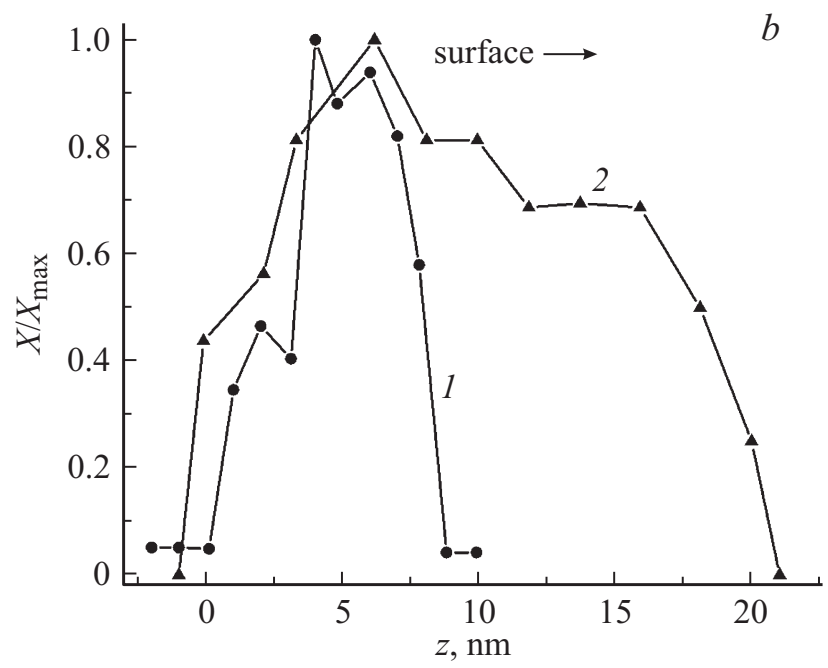

Рис. 4. $a-$ электронно-микроскопическое изображение поперечного среза структур с КТ (сверху) и КЯ/КТ (снизу) в сканирующем режиме. $b$ - относительное содержание In в КТ в структурах с КТ (1) и КЯ/КТ (2), полученное методом рентгеновской энергодисперсионной спектроскопии по линиям, отмеченным на $a$. 
глубже. Изменение профиля квантующего потенциала, как показано в [6], оказывает более сильное влияние на волновую функцию дырки, которая имеет бо́льшую эффективную массу и сильнее локализована в области минимума по сравнению с электроном, у которого эффективная масса на порядок меньше.

\section{4. Заключение}

Комплексное применение методов фотоэлектрической спектроскопии и просвечивающей электронной микроскопии, а также исследование квантово-размерного эффекта Штарка на экситонах в КT InAs/GaAs, выращенных газофазной эпитаксией из металлорганических соединений при атмосферном давлении, позволило установить, что при заращивании массива КT InAs-слоем КЯ InGaAs происходит уменьшение энергии основного оптического перехода в КТ и увеличение аномального дипольного момента экситона в основном состоянии КТ. Наблюдаемые эффекты объясняются увеличением эффективного размера КТ за счет обогащения области вблизи вершины КТ индием.

Авторы выражают благодарность вед. науч. сотр. НИФТИ ННГУ Б.Н. Звонкову за выращивание структур.

Работа выполнена при поддержке государственного задания Министерства образования и науки России (4.8337.2017/БЧ).

\section{Список литературы}

[1] V.M. Ustinov, A.E. Zhukov, A.R. Kovsh, S.S. Mikhrin, N.A. Maleev, B.V. Volovik, Yu.G. Musikhin, Yu.M. Shernyakov, E.Yu. Kondat'eva, M.V. Maximov, A.F. Tsatsul'nikov, N.N. Ledentsov, Zh.I. Alferov, J.A. Lott, D. Bimberg. Nanotechnology, 11 (4), 397 (2000).

[2] S.S. Mikhrin, A.R. Kovsh, I.L. Krestnikov, A.V. Kozhukhov, D.A. Livshits, N.N. Ledentsov, Yu.M. Shernyakov, I.I. Novikov, M.V. Maximov, V.M. Ustinov, Zh.I. Alferov. Semicond. Sci. Technol., 20 (5), 340 (2005).

[3] B. Shi, S. Zhu, Q. Li, Y. Wan, E.L. Hu, K.M. Lau. ACS Photonics, 4 (2), 204 (2017).

[4] Б.В. Воловик, А.Ф. Цацульников, Д.А. Бедарев, А.Ю. Егоров, А.Е. Жуков, А.Р. Ковш, Н.Н. Леденцов, М.В. Максимов, Н.А. Малеев, Ю.Г. Мусихин, А.А. Суворова, В.М. Устинов, П.С. Копьев, Ж.И. Алфёров, Д. Бимберг, П. Вернер. ФТП, 33 (8), 990 (1999).

[5] K. Nishi, H. Saito, S. Sugou, J.-S. Lee. Appl. Phys. Lett., 74, 1111 (1999).

[6] W. Sheng, J.P. Leburton. Phys. Rev. B, 63, 161301 (2001).

[7] Б.Н. Звонков, И.А. Карпович, Н.В. Байдусь, Д.О. Филатов, С.В. Морозов. ФТП, 35 (1), 92 (2001).

[8] Gatan, Inc. Precision Ion Polishing System User's Guide Revision, Coronade Lane, Pleasanton, Ca, Nov. 3, 1998.

[9] И.А. Карпович, Б.Н. Звонков, С.Б. Левичев, Н.В. Байдусь, С.В. Тихов, Д.О. Филатов, А.П. Горшков, С.Ю. Ермаков. ФТП, 38 (4), 448 (2004).
[10] P.W. Fry, I.E. Itskevich, D.J. Mowbray, M.S. Skolnick, J.J. Finley, J.A. Barker, E.P. O'Reilly, L.R. Wilson, I.A. Larkin, P.A. Maksym, M. Hopkinson, M. Al-Khafaji, J.P.R. David, A.G. Cullis, G. Hill, J.C. Clark. Phys. Rev. Lett., 84, 733 (2000).

[11] А.П. Горшков, И.А. Карпович, А.В. Кудрин. Поверхность. Рентгеновские, синхротронные и нейтронные исследования, 5, 25 (2006).

[12] T.M. Hsu, W.-H. Chang, C.C. Huang, N.T. Yeh, J.-I. Chyi. Appl. Phys. Lett., 78, 1760 (2001).

Редактор Г.А. Оганесян

\section{Influence of the cap layer composition on the electronic properties of $\operatorname{InAs} / \mathrm{GaAs}$ quantum dots}

\author{
A.P. Gorshkov ${ }^{1}$, N.S. Volkova ${ }^{2,3}$, P.G. Voronin ${ }^{1}$, \\ A.V. Zdoroveyshchev ${ }^{2}$, L.A. Istomin ${ }^{3}$, D.A. Pavlov ${ }^{1}$, \\ Yu.V. Usov ${ }^{1}$, S.B. Levichev ${ }^{2}$ \\ ${ }^{1}$ Lobachevsky State University of Nizhny Novgorod, \\ 603950 Nizhny Novgorod, Russia \\ ${ }^{2}$ Physico-Technical Research Institute, \\ Lobachevsky State University of Nizhny Novgorod, \\ 603950 Nizhny Novgorod, Russia \\ ${ }^{3}$ Research Institute for Chemistry, \\ Lobachevsky State University of Nizhny Novgorod, \\ 603950 Nizhny Novgorod, Russia
}

\begin{abstract}
The covering of the array of self-assembled InAs/GaAs quantum dots by the layer of the InGaAs quantum well leads to an increase of their size due to the indium enrichment of the region near the top of the quantum dots, which reduces the energy of the ground state optical transition at quantum dots by $50 \mathrm{meV}$ and shifts the hole wave function toward the top of the quantum dot.
\end{abstract}

